\title{
PREVALENCE OF BRUCELLOSIS IN PIGS: THE FIRST REPORT IN BANGLADESH
}

\author{
M. S. Rahman ", M. Nuruzzaman, M. S. Ahasan, R. R. Sarker, A. Chakrabartty, A. Nahar, M. J. Uddin, M. A. S. \\ Sarker and L. Akhter ${ }^{1}$
}

Department of Medicine, Bangladesh Agricultural University, Mymensingh 2202, Bangladesh

${ }^{1}$ DLS, Krishi Khamar Sarak, Farmgate, Dhaka1215, Bangladesh

\begin{abstract}
Brucellosis, a bacterial zoonotic disease, has been reported in ruminants but still no report in pigs in Bangladesh. The aim of this study was to describe seroprevalence of brucellosis in swine in Bangladesh. Blood from a total of 105 pigs was collected from selected areas of Bangladesh. All samples were screened using Rose Bengal Test (RBT) and further confirmed by using Slow Agglutination Test (SAT). A structured questionnaire was used to collect the epidemiological data related to the animals and husbandry practices. Out of the 105 sera analyzed, $7(6.7 \%)$ and $5(4.8 \%)$ were found to be positive by RBT and SAT respectively. It was observed that, insignificantly higher prevalence of brucellosis based on SAT was found in female (5.6\%) than male $(2.9 \%)$, in aged animal $(8.1 \%)$ than young $(0.0 \%)$ and in pregnant animal $(12.5 \%)$ than non pregnant animal $(2.1 \%)$ ( $p>0.05$ ). Prevalence of brucellosis was $42.9 \%$ in aborted pigs and $1.6 \%$ in non aborted pigs. The association between abortion status and prevalence of brucellosis was statistically highly significant $(\mathrm{p}<0.01)$. This report of prevalence of brucellosis in pigs is very important with regards to the human health and other livestock and might help Government and NGOs to design preventive measurement and establish livestock health policy.
\end{abstract}

Key words: Prevalence, Swine, Brucellosis, Bangladesh

\section{INTRODUCTION}

Brucellosis in pigs caused by Brucella suis, a bacterial infection causes bacteraemia and chronic inflammation in the reproductive organs of both sexes. Five different biovars of $B$. suis cause infection in animals other than pigs such as rain deer, caribou, hares and various murine species and occasionally in cattle and dogs (Godfroid et al., 2002). The capability of B. suis to colonize the bovine udder with subsequent shedding in milk means that it has the potential to be a serious human health risk. Outbreaks in slaughter houses have been caused by inhalation of $B$. suis. Most cases occur in people employed in meat processing industry and animals rearing while sources include the domestic cattle, pig, sheep, goat and unpasteurized dairy products (Radostits, 2000).

Though, out of 590 million pigs in the world, about $34 \%$ are raised in tropical countries. Due to the religious point of view and for the limited number of pork consumers, the pig population is not large compared to other ruminants and birds in Bangladesh. Furthermore, it is difficult to get the exact number of pigs in Bangladesh. But the pig population is increasing in the tribal areas. Due to the high number of piglet born, easy rearing with available natural resources, high disease resistance and low production cost, pig rearing is getting importance in the tribal regions to eliminate poverty. Such as in study areas, there are some tribal communities are rearing pigs by receiving asset grant from the FSUP (Food Security for the Ultra Poor) project funded by European Union. These pigs are predominantly belongs to the native and indigenous dwarf type producing low quality pork. The pig rearing continues to be primitive scavenging in nature because they are raised by certain rural people who are educationally, economically and socially most backward. Therefore, it has a great value to identify brucellosis in pigs because of socioeconomic impacts of rural ultra poor people.

In Bangladesh, brucellosis in cattle (Rahman et al., 2011a, 2010, 2009, 2006; Amin et al., 2005), buffalo (Rahman et al., 2006), sheep (Rahman et al., 2011b; Rahman et al., 2008; Uddin et al., 2007b), goat (Rahman et al., 2011b; 2008; Uddin et al., 2007b) have been reported that are causing huge economic losses to the livestock industry. The diagnosis of brucellosis is confirmed by isolation of Brucella by bacteriological culture or by the detection of an immune response by serological test to its antigens (Orduna et al., 2000). But the diagnosis of brucellosis based exclusively on Brucella isolation presents several drawbacks. Like the slow growth of Brucella may delay diagnosis for more than 7 days and also, the sensitivity is often low ranging from 50 to $90 \%$ depending on disease stage, culture medium, quantity of bacteria and culture technique employed (Gotuzzo et al., 1986).

*Corresponding e-mail address: prithu102@yahoo.co.uk

Copyright (C) 2011 Bangladesh Society for Veterinary Medicine All rights reserved 0248/2012 


\section{S. Rahman and others}

Hence, the serological tests are important for diagnosis of brucellosis. Serological test like the Rose Bengal Test (RBT), Slow Agglutination Test (SAT), Mercaptoethanol test and Enzyme Linked Immunosorbent Assay (ELISA) are generally used for the detection of Brucella infection in animal. To the best of knowledge, there is no published report of brucellosis of pig in Bangladesh. Therefore, the aim of this study was to determine the seroprevalence of brucellosis in pigs for the first time in Bangladesh by Rose Bengal Test (RBT) as screening test and later by Slow Agglutination Test (SAT) as confirmatory test.

\section{MATERIALS AND METHODS}

\section{Blood and sera samples collection}

A total of 105 blood samples (Table 1) were collected from two different districts of Bangladesh. Where there was availability of chute, pig was entered into the chute and restrained but where chute was not available, the pig was controlled by the owner and attendant. The site of blood collection at ear vein or tail vein was soaked with tincture of iodine or alcohol before collecting blood. About 5-7 $\mathrm{ml}$ of blood was collected with the help of sterile disposable syringe and needle and was kept undisturbed on a tray for at least 1 hour at room temperature in a slightly inclined position to facilitate clotting. The clotted blood samples with sera were transferred to refrigerator at $4{ }^{\circ} \mathrm{C}$ and kept overnight. Later on, the sera were poured into the separate test tube from each labeled syringe and the test tube was marked with same number by permanent marker. Clear sera were collected following centrifugation at $3000 \mathrm{rpm}$ for 10 minutes and were transferred to the sterilized labeled eppendorf tube and stored at $20^{\circ} \mathrm{C}$ until used. A structured questionnaire was used to collect epidemiological data of the animals. Before analyzing the data, the questionnaire data was rechecked.

Table 1. Sera samples collected from pigs in Sirajgang and Bogra district

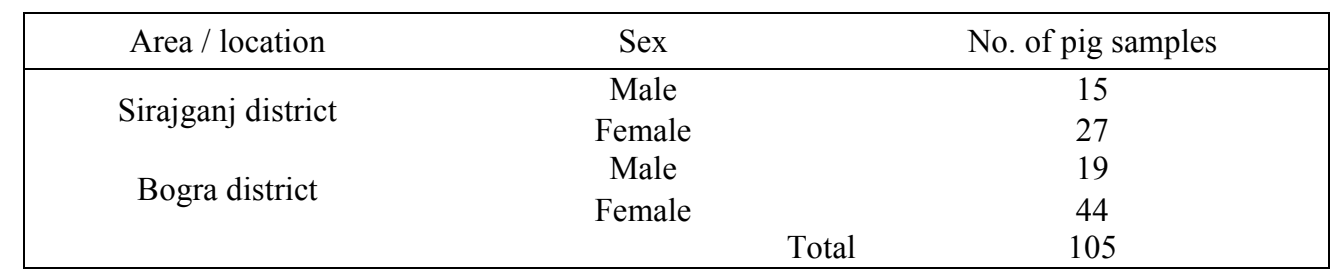

\section{Serological tests}

\section{Rose Bengal Test (RBT)}

The RBT was performed according to the procedure as described by Uddin et al. (2007a, 2007b). The test serum samples and Brucella abortus antigen (William James House, Cowley Rd. Cambridge, CB4 0WX, UK) were kept 1 hour in room temperature before beginning the test. $30 \mu 1$ of each serum to be tested was placed on a glass plate circled approximately $2 \mathrm{~cm}$ in diameter. Then the vial of antigens was shacked gently and $30 \mu 1$ of antigen was put beside each of the sera. The antigens and the serum were mixed on the plate with a stirrer and spread over the entire area enclosed by the circle. Then the plate was placed on a mechanical rotator at 80-100 rpm for 4 minutes and the reading was taken immediately. Any agglutination or precipitation was considered as positive, whereas no reaction (negative) indicated the absence of Brucella antigen in the sera.

\section{Slow Agglutination Test (SAT)}

SAT was carried out with EDTA. The SAW (Synbiotics, concentrated suspension of B. abortus, Weybridge, stain 99) antigen was diluted @1 $1 \mathrm{ml}$ antigen with $19 \mathrm{ml} \mathrm{SAT}$ buffer solution. The SAT buffer was prepared by adding $0.93 \mathrm{gm}$ EDTA $\left(5 \mathrm{mM}\right.$, Triplex $\left.{ }^{\circledR}\right)$ with $500 \mathrm{ml}$ PBS, where PBS was prepared by adding 5 tablets of PBS (Dulbecco-A, Oxoid, UK) in $500 \mathrm{ml}$ distilled water. Briefly, the slow agglutination test was performed in flat bottom 96 well micro plates. At first for each test serum, a row of 3 wells of the 96 well micro plates was selected to make double dilution of the sera. $168 \mu \mathrm{l}$ of SAW buffer was pipette in first well and $100 \mu 1$ in the2nd well and 3rd well of the micro plate, respectively Then $32 \mu \mathrm{l}$ of serum was added in 1 st well (dilution 1/6.25) after well mixing of the serum and PBS EDTA in the 1st well and $100 \mu 1$ was taken from this well and was placed in the second well (1/12.5). 
One hundred microliter $(100 \mu \mathrm{l})$ from the 2 nd well was transferred into the 3rd well and finally $100 \mu \mathrm{l}$ of liquid in excess was discarded from 3rd well. Note that, all wells contained $100 \mu 1$. Then in each well $100 \mu l$ of standardized SAW antigen was added. This gives the serial serum dilution of $1 / 12.5,1 / 25,1 / 50$. The plate was then incubated at $37^{\circ} \mathrm{C}$ for 24 hours $(+/-4 \mathrm{hrs})$ for reading. After 24 hours, the agglutination reaction was observed by using a magnifying mirror against illumination source. Notably, for every group of samples tested, a positive control serum was included. Reading was taken on the basis of this protocol and the standardization was performed (75\% agglutination of the OIEISS). The results were interpreted according to instruction of Veterinary Agrochemical Research Center (Groeselenberg 99, 1180 Brussels, Belgium).

\section{Statistical analysis}

The results were statistically analyzed by z-test for proportions based on the result of both tests in terms of age, sex, abortion, pregnancy status and study area. A probability associated with the observed values was determined from relevant tables and significance was determined at $5 \%$ level.

\section{RESULTS AND DISCUSSION}

Brucellosis is an important zoonosis and serological surveillance is essential for its control (Erdenebaatar et al., 2004). The importance of brucellosis was primarily due to its public health significance and economic loss. Additionally, pigs infected with brucellosis can serve as a source of infection to other domestic animals. Bangladesh is an endemic area for brucellosis. This study investigates the serological status of brucellosis of pigs in selected areas of Sirajganj and Bogra districts of Bangladesh using RBT and SAT. This study helps to understand the epidemiology of Brucella in pig, to buildup awareness and to provide information for disease control in animals and human being. Seropositivity to be considered due to natural infection occurred because vaccination for brucellosis in pigs has never been practiced in Bangladesh.

Out of 105 pigs sera examined using Rose Bengal Test (RBT), 7 pigs showed positive reaction with a prevalence of brucellosis $6.7 \%$. It was shown that 5 pigs were sensitive to brucellosis in SAT with a prevalence of $4.8 \%$. Seroprevalence of brucellosis was higher in RBT $(6.7 \%)$ than SAT (4.8\%) (Table 2). This finding is little higher than a previous report of prevalence (3\%) of brucellosis in pigs by Meng et al. (2009) and lower than the seroprevalence $(7.5 \%)$ of brucellosis determined by Watarai et al. (2006). The prevalence and severity of disease may vary with the breed, geographic location, type of diagnostic test, husbandry and environmental factor as well as the biovar of the organism (Amin et al., 2005). Since in Bangladesh, pigs are usually reared in backyard or in the field as free range system, they are getting slow dose of infection to several infectious agents regularly and are thought to be resistant to most disease due to the presence of antibodies. However, this hypothesis difficult to prove since there is no study has been conducted with pigs in Bangladesh.

Table 2. Seropositive rate of brucellosis in Pigs based on RBT and SAT

\begin{tabular}{|llllll|}
\hline \begin{tabular}{l} 
Total $\begin{array}{l}\text { No. of } \\
\text { samples tested }\end{array}$ \\
\cline { 2 - 5 }
\end{tabular} & by RBT & by SAT & by RBT & by SAT \\
\hline 105 & 7 & 5 & $7(6.7 \%)$ & $5(4.8 \%)$ \\
\hline
\end{tabular}

RBT $=$ Rose Bengal Test SAT $=$ Slow Agglutination Test

With regards to the age, the results of this study showed a higher prevalence within the 3-4 years age group compared to the age group of 2-3 years age. Whereas no positive sera were detected in 1-2 years old pigs in both tests. Additionally, RBT showed more reactivity than SAT at 3-4 years age group (Table 3 ). The finding is coincided with the observation of Ruiz-Fons et al. (2006). The older animals supposed to be more infected, because of more contact with infectious agents and sometimes become susceptible from malnutrition during pregnancy. But there was no significant statistical association between age group and the prevalence $(p>0.05)$. The antibody titer against $B$. abortus is associated with low prevalence in young stock than the adults (Ahmed and Munir, 1995). Kazi et al. (2005) reported higher prevalence of infection in animals more than 4 years of age compared to younger animals. It appears that the higher prevalence of brucellosis among older pigs might be related to maturity with the advancing age. Thereby, the organism may have propagated to remain either as latent infection or it may cause clinical manifestation of the disease (Kazi et al., 2005). 


\section{S. Rahman and others}

Notably, it is difficult to compare our results since no such study was conducted in pigs in Bangladesh. Out of 105 pigs, 71 were female and 34 were male. 5 female showed positive reaction in RBT with a prevalence of $7 \%$ and 4 female showed positive reaction in SAT with a prevalence of $5.6 \%$. The male showed positive reactivity with a prevalence of $5.9 \%$ by RBT and $2.9 \%$ by SAT. Higher prevalence of brucellosis was found in female than male but the association was non-significant $(\mathrm{p}>0.05)$ (Table 3$)$. The prevalence of brucellosis in relation to the sex of animals was reported by some researchers and found significantly higher prevalence in females than in males (Hussein et al., 2005), whereas MacMillan et al. (1982) showed that B. abortus causes intermittent bacterimea in the mares but not in the stallions. Uddin et al. (2007a, 2007b) found relationship between brucellosis and sex. Muma et al. (2006) could not find any association between Brucella antibody titers and sex. In this study, total 24 sows were pregnant. Higher prevalence of brucellosis was found in pregnant sows than non pregnant sows that was $12.5 \%$ and $4.3 \%$ by RBT, and $12.5 \%$ and $2.1 \%$ by SAT, respectively (Table 3 ). But this relationship is not statistically significant $(\mathrm{p}<0.05)$. Brucellosis is essentially a disease of the sexually mature animals. The predilection site is the reproductive tract, especially the gravid uterus. Allantoic factors, including erythritol possibly steroid hormones and other substances stimulate the growth of most of the Brucellae (Radolf, 1994). Erythritol, a sugar alcohol synthesized in the ungulate placenta and stimulates the growth of virulent strains of $B$. abortus, has been credited with the preferential localization of this bacterium within the placenta of ruminants (Smith et al., 1962).

Among 71 sows, 7 sows had previous record of abortion. The prevalence of brucellosis in aborted sows was $42.9 \%$ in both RBT and SAT, while the non-aborted sows showed the prevalence of brucellosis $3.1 \%$ in RBT and $1.6 \%$ in SAT (Table 3). It was found that the prevalence of brucellosis was significantly $(\mathrm{p}<0.01)$ higher in aborted or previously aborted sows than the sows having no record of abortion when the sera samples tested by RBT and SAT. Ibrahim and Habiballa (1975) reported a prevalence of brucellosis 14.2\% in cows that had aborted previously. Other researchers had reported similar findings (Shaw, 1986; Barman et al., 1989; Sandhu et al., 2001). Rahman et al. (2006) reported cows with a history of retained placenta, had a prevalence of brucellosis $8.70 \%$ and there was a statistically significant difference in the prevalence of brucellosis and history of retained placenta.

Table 3. Demographic related seroprevalence of brucellosis in pigs based on RBT and SAT

\begin{tabular}{|cccc|}
\hline & Sera tested & Positive (\%) by RBT & Positive (\%) by SAT \\
\hline Age & & & $0(0.0 \%)$ \\
1 to 2 years & 40 & $0(0.0 \%)$ & $2(7.1 \%)$ \\
2 to 3 years & 28 & $2(7.1 \%)$ & $3(8.1 \%)$ \\
3 to 4 years & 37 & $5(13.5 \%)$ & $1(2.9 \%)$ \\
Sex & & & $4(5.6 \%)$ \\
Male & 34 & $5(7.9 \%)$ & $3(42.9 \%)$ \\
Female & 71 & $3(42.9 \%)$ & $1(1.6 \%)$ \\
History of abortion* & 7 & $2(3.1 \%)$ & $3(12.5 \%)$ \\
Yes & 64 & & $1(2.1 \%)$ \\
No & & $3(12.5 \%)$ & \\
History of pregnancy & 24 & $2(4.3 \%)$ & \\
Yes & 47 & & \\
No & & & \\
\hline
\end{tabular}

* Significant at $1 \%$ level $(\mathrm{p}<0.01)$ RBT= Rose Bengal Test SAT= Slow Agglutination Test

In Sirajganj district, the prevalence was $6.7 \%$ in male and $7.4 \%$ in female and overall prevalence was $7.1 \%$ by RBT. There was no positive reaction to SAT in male but the prevalence in female was $4.76 \%$ with a overall prevalence $4.8 \%$ in Sirajganj district by SAT (Table 4). In Bogra district, the prevalence was 5.3\% and $6.8 \%$ by RBT and $5.3 \% \& 4.5 \%$ by SAT in case of male and female animal, respectively. The overall prevalence in Bogra district was $6.6 \%$ by RBT and $4.8 \%$ by SAT (Table 4 ). In this study, statistically insignificant higher prevalence of brucellosis was found in Bogra $(6.6 \%)$ district than Sirajganj district $(7.1 \%)$ by RBT $(\mathrm{p}>0.05)$. But the prevalence was same $(4.8 \%)$ in both district determined by SAT. 
Prevalence of brucellosis in pigs: the first report in Bangladesh

Table 4. Area/location related seroprevalence of brucellosis in pigs based on RBT and SAT

\begin{tabular}{|ccccccc|}
\hline Location & Sex & Sera tested & $\begin{array}{c}\text { No. (\%) of } \\
\text { positive by RBTpositive by RBT }\end{array}$ & $\begin{array}{c}\text { No (\%) of } \\
\text { positive by SAT }\end{array}$ & $\begin{array}{c}\text { No.(\%) of } \\
\text { positive by SAT }\end{array}$ \\
\hline \multirow{2}{*}{ Sirajganj } & Male & 15 & $1(6.7 \%)$ & $3(7.1 \%)$ & $0(0.0 \%)$ & $2(4.8 \%)$ \\
& Female & 27 & $2(7.4 \%)$ & & $2(4.8 \%)$ & $1(5.3 \%)$ \\
\multirow{2}{*}{ Bogra } & Male & 19 & $1(5.3 \%)$ & $4(6.6 \%)$ & $2(4.5 \%)$ & $3(4.8 \%)$ \\
& Female & 44 & $3(6.8 \%)$ & & \\
\hline
\end{tabular}

RBT $=$ Rose Bengal Test SAT= Slow Agglutination Test

Ghani et al. (1998) and Uddin et al. (2007a, 2007b) stated that several factors such as age, sex, breed, location, herd size and living condition influence the seroprevalence of brucellosis. It is important to remember that brucellosis is an important zoonosis and nearly every case of human brucellosis has an animal origin and, therefore, control is primarily a veterinary responsibility (Nicoletti, 1992). The Brucellae are 'survivors' in both extracellular and intracellular environments. Compatible relationships with the hosts including variable incubation periods, asymptomatic carriers and resistance to treatments are the important problems. The animal husbandry factors such as commerce, nomadism, commingling, and increasing population sizes assure difficulties in control of diseases. To the best of our knowledge, this is the first report of seroprevalence of brucellosis in pigs in Bangladesh. Regular sero-monitoring of the pigs, culling of positive reactors from breeding program are important to eradicate or control of this zoonotic disease. Further studies for isolation, identification and typing of specific Brucella sp. are recommended.

\section{ACKNOWLEDGEMENTS}

The authors are grateful to pig farmers and pig farm owners for allowing the study with their pig. The authors are also grateful to Dr. A. K. M. Anisur Rahman, Department of Medicine, Bangladesh Agricultural University, Mymensingh 2202, Bangladesh for supplying the SAT facilities.

\section{REFERENCES}

1. Ahmed R and Munir MA (1995). Epidemiological investigations of brucellosis in horses, dogs, cats and poultry. Pakistan Veterinary Journal 15: 85-88.

2. Amin KMR, Rahman MB, Sarkar SK, Kabir SML and Akand MSI (2005). Serological epidemiology of brucellosis in cattle of the Mymensingh district of Bangladesh. Journal of Animal and Veterinary Advances 3: 898-900.

3. Barman NN, Ahmed K, Saikia GK and Boro BR (1989). Seroprevalence of brucellosis in organized cattle farms of Assam (India). Indian Journal of Animal Health 28: 99-102.

4. Erdenebaatar J, Bayarsaikhan B, Yondondorj A, Watarai M, Shirahata T, Jargalsaikhan E, Kawamoto K and Makino S (2004). Epidemiological and serological survey of brucellosis in Mongolia by ELISA using sarcosine extracts. Microbiology and Immunology 48: 571-577.

5. Ghani M, Zeb A, Siraj M and Naeem M (1998). Sero-incidence of bovine brucellosis in Peshawar district of Pakistan. Indian Journal of Animal Science 68 (5): 457.

6. Godfroid J and Kasborer A (2002). Brucellosis in the European Union and Norway at the turn of the twenty first century. Veterinary Microbiology 90: 135-145.

7. Gotuzzo E, Carrillo C, Guerra J and Liosa L (1986). An evaluation of diagnostic methods for brucellosis-the value of bone marrow culture. Journal of Infectious Diseases 153: 122-125.

8. Hussein AAA, Sayed ASM and El Feki MA (2005). Seroepidemiological study on human brucellosis in Assiut Governorate. Egyptian Journal of Immunology 12: 49-56.

9. Ibrahim AE and Habiballla N (1975). A survey of brucellosis in Messeriya cows of Sudan. Tropical Animal Health and Production 7: 245-246.

10. Kazi MAR, Rahman MB, Rahman MS, Han J, Park J and Chae JS (2005). Prevalence of Brucella antibodies in sera of cows in Bangladesh. Journal of Veterinary Science 6: 223-226.

11. MacMillan AP, Baskerville A, Hambleton P and Corbel MJ (1982). Experimental Brucella abortus infection in the horse: observations during the three months following inoculation. Research Veterinary Science 33: 16-19. 


\section{S. Rahman and others}

12. Meng XJ, Lindsay DS and Sriranganathan N (2009). Wild boars as sources for infectious diseases in livestock and humans. Philosophical Transactions of the Royal Society B: Biological Sciences 364(1530): 2697-2707.

13. Muma JB, Samui KL, Siamudaala VM, Oloya J, Matope G, Omer MK, Munyeme M, Mubita C and Skjerve E (2006). Prevalence of antibodies to Brucella spp. and individual risk factors of infection in traditional cattle, goats and sheep reared in livestock-wildlife interface areas of Zambia. Tropical Animal Health and Production 38: 195-206.

14. Nicoletti P (1992). The control of brucellosis-a veterinary responsibility. Saudi Medical Journal 13: $10-133$.

15. Orduna A, Almaraz A, Prado A, Gutierrez PM, Garcia-Pascual A, Duenas A, Cuervo M, Abad R, Hernandez B, Lorenzo B, Bratos MA and Torres AR (2000). Evaluation of an immunocapture-agglutination test (Brucellacapt) for serodiagnosis of human brucellosis. Journal of Clinical Microbiology 38: 4000-4005.

16. Radostits OM, Gay CC, Blood DC and Hinchcliff KW (2000). Veterinary Medicine. 9th edn., W.B. Saunders Company Ltd, London. pp: 871-882.

17. Radolf JD (1994). Brucellosis: don't let it get your goat. American Journal of Medical Science 307: 64-75.

18. Rahman MS, Han JC, Park J, Lee JH, Eo SK and Chae JS (2006c). Prevalence of brucellosis and its association with reproductive problems in cows in Bangladesh. Veterinary Record 159: 180-182.

19. Rahman MS, Faruk MO, Her M, Kim JY, Kang SI and Jung SC (2011a). Prevalence of brucellosis in ruminants in Bangladesh. Veterinarni Medicina 56: 379-385.

20. Rahman MS, Hahsin MO, Ahasan MS, Her M, Kim JY, Kang SI and Jung SC (2011b). Brucellosis in sheep and goat of Bogra and Mymensingh district of Bangladesh. Korean Journal of Veterinary Research 51: 277-280.

21. Rahman MS, Huque MF, Ahasan MS and Song HJ (2010). Indirect enzyme linked immunosorvent assay for the diagnosis of Brucellosis in cattle. Korean Journal of Veterinary Service 33: 113-119.

22. Rahman MS, Alam N, Rahman AKMA, Huque AKMF, Ahasan MS and Song HJ (2009). Seroprevalence of specific Brucella infection of cattle in Bangladesh Agricultural University Veterinary Clinics and its surrounding areas. Korean Journal of Veterinary Service 32: 219-225.

23. Rahman MS, Jahan N, Hossain MA, Uddin MJ, Niraj KS, Islam KBMS, Ahasan MS, Rahman AKMA and Song HJ (2008). Tube agglutination test is superior than other serological tests for diagnosis of brucellosis in small ruminants. Korean Journal of Veterinary Service 31: 493-496.

24. Rahman MS, Uddin JM, Park JH, Chae JS, Rahman MB and Hossain MA (2006). A short history of brucellosis: special emphasis in Bangladesh. Bangladesh Journal of Veterinary Medicine 4: 1-6.

25. Ruiz-Fons F, Starnes CT and Kennard R (2006). Seroprevalence of six reproductive pathogens in European wild boar (Sus scrofa) from Spain: the effect on wild boar female reproductive performance. Theriogenology 65: 731743.

26. Sandhu KS, Filia G, Sharma DR, Dhand NK, Singh J and Saini SS (2001). Prevalence of brucellosis among dairy animals of Punjab. Indian Journal of Comparative Microbiology 22: 160161.

27. Shaw AA (1986). Studies on infection, infertility and abortion incidence of bovine brucellosis in Kashmir. Veterinary Bulletin 57: 625-627.

28. Smith H, Williams AE, Pearce JH, Keppie J, Harris-Smith PW, Fitz-George RB and Witt K (1962). Foetal erythritol: a cause of the localization of Brucella abortus in bovine contagious abortion. Nature 193: 47-49.

29. Uddin JM, Rahman MS, Hossain MA, Akter SH, Majumder S, Park JH and Song HJ (2007a). Relation between brucellosis and husbandry practices in goats in Bangladesh. Korean Journal of Veterinary Service 30: 259-267.

30. Uddin JM, Rahman MS, Akter SH, Hossain MA, Islam MT, Islam MA, Park JH and Song HJ (2007b). Seroprevalence of brucellosis in small ruminants in selected area of Bangladesh. Korean Journal of Veterinary Service 30: 511-525.

31. Watarai M, Ito N, Omata Y and Ishiguro N (2006). A serological survey of Brucella spp. in free-ranging wild boar (Sus scrofa leucomystax) in Shikoku, Japan. Journal of Veterinary Medical Science 68: 1139-1141. 